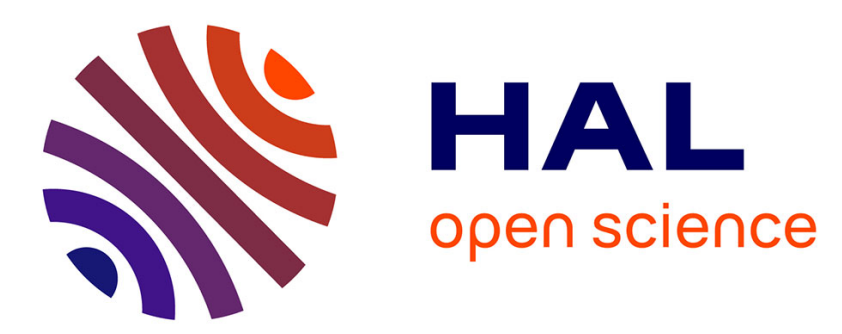

\title{
A longitudinal study of driving instructor guidance from an activity-oriented perspective
}

V. Boccara, Christine Vidal-Gomel, J. Rogalski, P. Delhomme

\section{To cite this version:}

V. Boccara, Christine Vidal-Gomel, J. Rogalski, P. Delhomme. A longitudinal study of driving instructor guidance from an activity-oriented perspective. Applied Ergonomics, 2015, 46, pp.21-29. 10.1016/j.apergo.2014.06.001 . halshs-01142409

\section{HAL Id: halshs-01142409 \\ https://shs.hal.science/halshs-01142409}

Submitted on 26 Aug 2020

HAL is a multi-disciplinary open access archive for the deposit and dissemination of scientific research documents, whether they are published or not. The documents may come from teaching and research institutions in France or abroad, or from public or private research centers.
L'archive ouverte pluridisciplinaire HAL, est destinée au dépôt et à la diffusion de documents scientifiques de niveau recherche, publiés ou non, émanant des établissements d'enseignement et de recherche français ou étrangers, des laboratoires publics ou privés. 


\title{
A longitudinal study of driving instructor guidance from an activity- oriented perspective
}

\author{
V. Boccara ${ }^{\mathrm{a},{ }^{*},}$, C. Vidal-Gomel ${ }^{\mathrm{b}}, \mathrm{J}_{\text {. Rogalski }}{ }^{\mathrm{c}}$, P. Delhomme ${ }^{\mathrm{d}}$ \\ a LIMSI-CNRS, B.P. 133, F-01403 Orsay Cedex, France \\ ${ }^{\mathrm{b}}$ Université de Nantes, CREN, Chemin de la censive du tertre, BP 81227, F-44312 Nantes cedex 3, France \\ ${ }^{\mathrm{c}}$ Université Paris 8 - Saint-Denis, CHArt, UFR de psychologie, 2, rue de la liberté, F-93526 Saint-Denis Cedex, France \\ d IFSTTAR, LPCM, 25, allée des marronniers, F-78000 Versailles, France
}

\begin{abstract}
The aim of this study was to provide a better understanding of the scaffolding activity of instructors during driving lessons in a French urban traffic context. It focuses on three common and risky tasks: turning right, turning left and overtaking. Data were based on fine-grained longitudinal analyses of the records of five driving lessons involving four student-instructor dyads. The instructor scaffolding activity was analyzed throughout training - an original approach in the sphere of driving. The results show that the instructors implemented the learning process using an integrative approach based on 'cutting' and 'decoupling' the driving task rather than the step-by-step method recommended in the curriculum. They transferred the responsibility of the driving components to the students in a similar order: 1) technical maneuvers, 2) situation identification and 3) goals focusing on other road-users. As expected, student autonomy and efficiency in driving increased as the training progressed. However, at the end of training, uncertainties remained with regard to the execution of basic sub-goals in complex situation; moreover, the instructors were still in charge of the navigational task. The results were discussed and suggestions were made to improve instructor training with a view to increasing their efficiency in teaching students.
\end{abstract}

\section{Introduction}

In this article, we present one component of a research program $^{1}$ relating to both the development of learner drivers' skills and the activity of professional instructors in the context of initial training in France (Boccara, 2011; Boccara, Delhomme, VidalGomel, \& Rogalski, 2011a, 2011b). The present paper aims to contribute to a better understanding of instructor scaffolding activity in the dominant context of training in French urban areas (Boccara, 2011).

Few studies examine trainers' scaffolding activity, despite the fact that trainers are recognized as a determinant of student

\footnotetext{
* Corresponding author.

E-mail addresses: boccara@limsi.fr, vincent.boccara@gmail.com (V. Boccara).

1 This research program was awarded a PHD grant by the French Ministry of Transportation via the intermediary of the INRETS (now IFSTTAR). The purpose was to provide a better understanding of teaching and learning processes involved in the French context of driver training (Boccara, 2011).
}

drivers' learning (Groeger, 2000; MERIT, 2005; Twisk et al., 2006; Bealand et al., 2013). In their literature review, Bealand, Goode, Salmon and Lenné (2013) emphasized for example the positive effects of driver training provided by professional trainers, but how these professionals proceed remains unknown. Studies by Groeger and Cleg $(2000,2007)$ showed that the total number of trainer interventions decreases throughout initial training. Rismark and Solvberg (2007) identified two decisive stages in instructor mediation: the selection of driving situations proposed to the learner and the clarification of learning objectives. In line with this research, we investigate more closely how instructors mediate the students' learning and how this mediation progresses during driver training. Several questions are then considered: how do instructors structure and organize the learning process to support the development of students' drivingskills? What are the driving goals they assigned to the students during lessons? How do these evolve throughout the driver training? 
1.1. Understanding instructors' scaffolding activity vis-à-vis students learning to drive

We consider that activity (and learning) is situated and depends on the characteristics of situations and the content and goals of the tasks given (Leplat, 1990, 1997; Hacker, 1985). This approach belongs to the "French-speaking framework" current which primarily focuses on the analysis of human activity in situations (Daniellou and Rabardel, 2005; Daniellou, 2005).

In the context of driver training, instructors support students' skills development through a scaffolding process ${ }^{2}$ that "enables a [child or] novice to solve a problem, carry out a task or achieve a goal which would be beyond his unassisted efforts. This scaffolding consists essentially of the [adult] 'controlling' those elements of the task that are initially beyond the learner's capacity, thus permitting him to concentrate on and complete only those elements that are within his range of competence." (Wood et al., 1976, p. 90).

First, trainers' activity is oriented toward their action to improve the trainees' skills (didactical dimension) and to satisfy professional requirements (Rogalski, 2003, 2005). The didactic activity involves selecting driving situations corresponding to the development of the trainees' skills and providing guidance in a more or less direct form, ranging from taking control of the vehicle to merely commenting on the driving situation (Vidal-Gomel et al., 2012). More particularly, trainers must ensure that trainees perform driving tasks which are encountered on a regular basis (depending on the type of area). The level of difficulty is then ensured by the trainer through the choice of traffic conditions (when possible) and his taking control of part of the driving activity (when adapting to actual traffic situations).

Driving instructors organize the learning progress in order to take account of the actual traffic flow conditions during each lesson, implying the simultaneous management of various driving goals (Weill-Fassina, 2005). In fact, they mediate between the current state of student drivers' skills and the driving situation through their tutoring activity, requiring them to assume responsibility for part of the task by acting directly on the vehicle commands, "cutting" and/or "decoupling" task goals, such as those identified above when considering the three focus tasks of driver training. "Cutting" and "decoupling" task goals are means used by trainers to control skill progression in training situations (Samurçay and Rogalski, 1998). In driver training, "cutting" goals is for example achieved by choosing "off-traffic" learning exercises, while "decoupling" occurs when trainers take charge of a driving task component.

Finally, instructors are involved in an organizational system. Instructors must apply common training instructions and progress. Furthermore, professional instructors in France guarantee the safety of the vehicle, its passengers and other road-users during driver training. In other words, they are legally responsible for the vehicle and could lose their trainer accreditation in the event of driving offences. Thus, the absence of physical and/or verbal intervention on the part of the instructor in relation to the student's driving performance could be considered an indicator that the student can manage the driving task at hand in a safe and adequate manner.
1.2. Goals of driver training: the contents of instructors' scaffolding activity?

Over the past decade, research based on the so-called GDE model (Goals of Driving Education, Siegrist, 1999) has focused on which driving skills student drivers should acquire (ADVANCED, 2002; INSERR, 2008; MERIT, 2005; NOVEV, 2004). It is expressed as a matrix organized into four hierarchical levels of goals: (1) vehicle maneuvering, (2) mastering driving situations, (3) goals and the context of driving (trip-related goals) and (4) goals for life and competencies for living (general goals); and three main axes: (1) knowledge and skills, (2) risk-increasing factors and (3) selfassessment (Hatakka et al., 2002; Siegrist, 1999). This matrix has influenced the driver training curriculum in several European countries. In France, the curriculum is a step-by-step learning progress with four steps (divided into a total of 180 specific objectives, DSCR, 2005): controlling the car at low or moderate speed, with little or no traffic (step 1); choosing the car's position on the road and crossing an intersection or turn (step 2); driving in normal traffic conditions on roads or in built-up areas (step 3); and being familiar with situations involving particular difficulties (step 4). In principle, instructors should transpose each of the 180 objectives into a learning situation, in a "cutting" process. However, this is not possible in the French context where training takes place in real traffic conditions in which goals must be combined (Vidal-Gomel and Rogalsky, 2007; Weill-Fassina, 2005). ${ }^{3}$ GDEs, such as the French curriculum, therefore constitute the instructors' prescribed tasks defining the training contents and the objectives that must be achieved at various granularity levels. However, these tasks are not modeling the driving activity, while the instructors' scaffolding activity is oriented towards supporting students learning. This calls for a driving activity framework which could guide the analysis of the trainers' scaffolding activity.

\subsection{A driving framework in an oriented activity perspective}

In line with the hierarchical model of driving, Lefebvre (2001) put forward a driving framework with four integrative components. (a) "Piloting the vehicle" (the "controlling" level) refers to using controls, controlling the vehicle and anticipating the effects of physical laws (inertia, trajectories, etc.). (b) "Traffic management" relates to the identification of driving situations and operational communication with other road-users. (c) "Navigation" refers to navigation in situation (short-term) and journey preparation (long-term). (d) A "meta-knowledge" component concerns selfawareness about driving and knowledge of one's own skills (Valot and Amalberti, 1992): it is related to each of the other three components. This framework assumes that the components are in constant interaction during driving and that they involve three dynamics: 1) the physical laws, integrated into the "piloting the vehicle" component, 2) the traffic, included in the "traffic management" and "Navigation" components, and 3) the driver's cognitive and psychical processes, concerning the two previous components.

The instructors' scaffolding activity should therefore support the students' learning process in order to integrate the following three goals and the first two dynamics involved in driving: 1) "technical" goals (TE) referring to vehicle management (trajectory, speed, etc.) organized into appropriate "maneuvers"; 2) "situation

\footnotetext{
${ }^{3}$ Moreover, the need to train such a combination was even identified for the highly proceduralized and technically-constrained pilot training, with the concept of "Line Oriented Flight Training" (LOFT).
}

\footnotetext{
2 "Scaffolding" is related to the concept of zone of proximal development (Vygotski, 1934/1986) defined by the "space" between what the learner is capable of doing with the help of others and what the learner can do or solve autonomously.
} 
identification" goals (SI) referring to the specific properties of the task context which have to be taken into account (type of traffic, infrastructure and signals, etc.) and, 3) goals "focusing on other road-users" (RU) (other vehicles, pedestrians, cycles, etc.) concerning the interaction with and adjustment to the behavior of other road-users.

In this perspective, the present study focuses on the nature and evolution of instructors' scaffolding activity throughout the initial driver training in France. We focused on three tasks: turning left (TL), turning right (TR) and overtaking (OT) (a stationary or slow-moving vehicle in urban traffic). ${ }^{4}$ These were chosen because 1 ) they are performed frequently in urban areas and during the driving lessons (Boccara, 2011), 2) they constitute an educational objective from the very beginning to the end of driver training (Boccara, 2011) while demonstrating a certain level of difficulty, and 3) they are risky for novice drivers and also during lay instruction (Twisk et al., 2006; Twisk, 1994, 1995; Gregersen et al., 2003). Thus, we wanted to identify 1) when, during training, instructors transfer the responsibility of the various components of driving activity according to Lefebvre's framework: piloting the vehicle, traffic management and navigation; 2) the progression of interventions related to specific subgoals in the three focus tasks (TL, TR and OT) and imbedded conditional sub-goals (vehicle controls such as stopping, starting, changing lane) which might be present, depending on the traffic context and 3) how the evolution of instructors' scaffolding activity is related with the increase in student driving performance.

\section{Method}

Inspired by Grounded Theory, the general orientation of our methodology is designed as an iterative process between theory, data and the definition of a method in which new questions emerge (Gason, 2004).

\subsection{Driving schools and participants}

Our study was conducted in two large driving schools in Paris city center, both of which were interested in having a better understanding of the instructors' activity during driver lessons, although they did not expect to obtain specific results. These schools belonged to the same group. They presented the same type of clientele, primarily young city-dwellers between 18 and 30 years old. ${ }^{5}$ They were located in the same area and their main economic activity was initial general driver training (with non-automatic cars). They also applied a similar policy concerning the continuity of student-instructor dyads throughout training in order to promote teaching consistency. These characteristics were key criteria in conducting our study for two reasons: first, taking over a new student during the first half of his training modifies the trainer's activity and second, students need more lessons before passing the test (Vidal-Gomel et al., 2012).

\footnotetext{
${ }^{4}$ Generally, roadways in Paris have two lanes, one lane in each direction, while some are one-way streets and others have two lanes in each direction. This infrastructure impacted both TL and OT: in the case of one-way streets, students have to change lanes by changing carriageways in order to overtake the vehicle, whereas in the case of two-way traffic they have to change into a lane going in the opposite direction. In the present study, overtaking tasks mainly fell into the first category.

5 These elements came from preliminary interviews with the directors of the driving schools.
}

Table 1

Characteristics of the participants, training sessions, instructor changes and number of lessons.

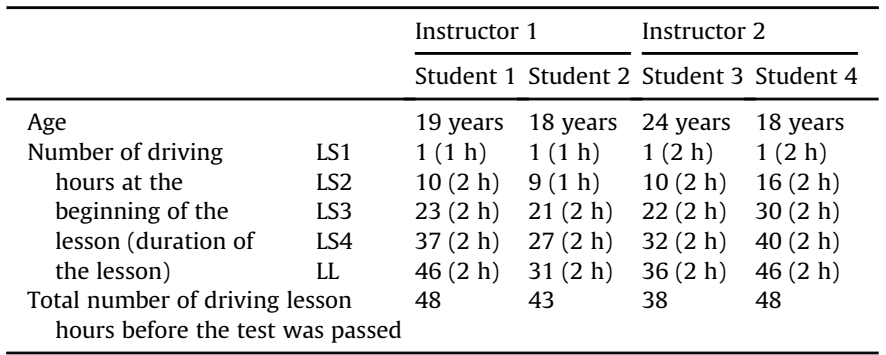

Note: LS1 = lesson step 1, LS2 = lesson step 2, LS3 = lesson step 3, LS4 = lesson step $4, \mathrm{LL}=$ last lesson. $37(2 \mathrm{~h})$ : lesson begins at the 37th training hour and lasts $2 \mathrm{~h}$.

The participants were four student-instructor dyads (all men). ${ }^{6}$ The four driving students were between 18 and 24 years old and had never driven a car before enrolling in the driving school (they had experience of the road environment as cyclists and car passengers). The two driving instructors differed in age but were both deemed experienced with respectively 3 and 15 years' experience as driving instructors. Table 1 presents the dyads in greater detail.

\subsection{Procedure}

The study was presented as research aimed at obtaining a better understanding of the students' skills development process and the activity of instructors during driving lessons. Both the students and instructors were assured that all records and analyses would remain strictly confidential and anonymous. The participants and directors of the two driving schools then authorized us to film all driving sessions. All the participants (students and instructors) volunteered for the study; they received no financial rewards.

The present method was based on an analysis of the progression of the instructors' scaffolding and the students' task performance during the driver learning process. The longitudinal method used involves observing the same people at two or more moments in time as they gain experience (Brown et al., 1999). It was therefore important for this study to follow stable studentinstructor dyads. The first lesson of each step of the French curriculum was observed. The number of driving hours differed for the four students at each step, but the students were at a similar stage in their learning progress. Three of the four students passed the test first time while the other one passed second time around. The data analysis was based on $36 \mathrm{~h}$ of recorded driving lessons (Table 1).

Driving lessons were recorded without the researcher being present in the vehicle because such a presence would disturb the natural context of the driving lessons. The driving lessons were filmed using an audio-video recording device on a tripod placed on the back seat of the vehicle (Fig. 1).

\subsection{Transcriptions and coding scheme}

The audio-video records were transcribed as completely as possible. The actions performed by the student and instructor were transcribed in parallel to the comments.

\footnotetext{
${ }^{6}$ We did not choose the dyads.
} 


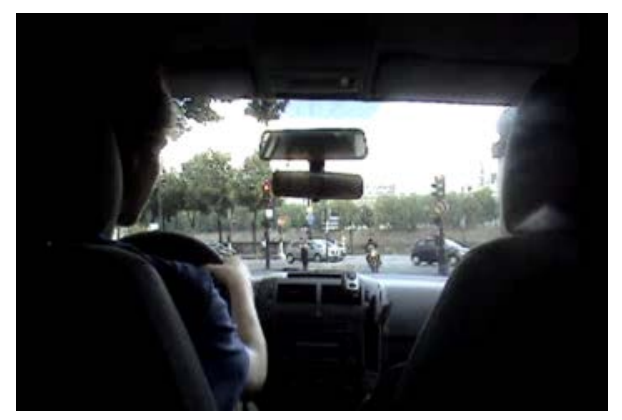

Fig. 1. Filmed driving scene.

A "predicate-arguments" coding scheme was used for comments. This type of coding has the characteristic of being both precise and sufficiently flexible to take account of both the form and content of the comment by using arguments related to the "deepness" of the analysis (Amalberti and Hoc, 1998). "Predicates" coded the shape of the instructor's comments to capture the degree of student guidance during driving (e.g. delegate, correct, request, etc.). Furthermore, the coding also consisted of two levels of "arguments" in order to take account of the content of the instructor's comments. The first level coded different information content (e.g. goals, procedures, rules, indicators, etc.) while the second level specified the content of comments relating to the driving activity (see, Appendix A). ${ }^{7}$

\subsection{Goals analysis in the focus tasks: turning right, turning left and overtaking}

For each focus task, the instructors' comments expressed goals that the students had to achieve in order to cope with the driving task. The main goals were divided into three categories (see, Fig. 2), depending on their role in driving: "identification of the situation" (IS) "road-user oriented" (RU) and "technical goals" (TE). The first and second categories of goals referred mainly to traffic management in Lefebvre's framework (2001), while the third referred to piloting. Conditional sub-goals referred to the achievement of driving sub-tasks possibly required to adjust to the situations encountered (Fig. 2).

\section{Results: the trainers' scaffolding activity}

In the present framework, results are organized according to a triple analysis of the student-instructor's activity during driver training: 1) the transfer of driving goals from instructor to student, 2) the time course of instructors' guidance and 3) the student performance of driving tasks without the instructor's assistance.

\footnotetext{
7 The finer and more precise cognitive and psychical dynamics cannot be studied using the present approach based on recorded observations of instructors' behavior (including communication) in natural settings. Such studies call for other methods - ranging from recording fine-grained cognitive operations in controlled driving tasks to provoking verbal information at appropriate moments. Highfidelity simulated driving situations would be an appropriate context for such analyses, although this type of simulation does not currently exist whereas some of them are described as "high-fidelity".
}

\subsection{Progressive task transfer from instructor to student}

The time course of transfers shown in Fig. 3 indicates how the instructors "uncoupled" and "coupled" the driving activity. They transferred the driving tasks incrementally in the same order throughout the driver training: vehicle controls, identify the driving situations, adapt driving to the current situation and improve driving for the final test (Fig. 3).

The vehicle controls were given to students in the same specific order. Each control transfer extended the range of possible actions for students. The next step was to give students the responsibility of identifying the characteristics of driving situations and to take local decisions in relation to completing the driving task, i.e. stopping, re-starting the vehicle and shifting gears if necessary. The instructors then continued to support the students in adjusting their driving to that of other road-users in terms of evaluating distances, speeds and behaviors. This task was transferred from the beginning of step 3. In step 4 and in the last lesson (LL), we observed that the instructors' main objective was to improve the students' driving performance in relation to the driving test (in particular ensuring better anticipation of other road users' behavior) more than expanding the learners' driving skills. However, they remained in charge of navigation until the last lesson of the driver training, except for students 1 and 2 who asked to manage a short, familiar journey (last lesson). Thus, students never completely managed navigation during lessons. This dimension of the driving task was not "recoupled" until the end of training. This was probably not a problem for students during the driving test, because in France it is the inspectors who give directions to students during the test. However, we may wonder about students' skills to manage their journey alone (or with a GPS for example) after passed their license, since there have not really been trained.

\subsection{Evolution of instructor guidance during training}

The progression of the trainer's instruction rate was different for the three invariant goals (Fig. 4a) and the four conditional subgoals (Fig. 4b) of the focus tasks. The instructors' support concerning the technical goals (TE) decreased progressively during the course of the training. Support relating to the identification of the situation goals (IS) and the road user-oriented goals (RU) increased between step 1 and step 2 before decreasing throughout the other steps (Fig. 4a, and "turning right", Fig. 4b). In fact, the increase was related to the "task-uncoupling" process initially adopted by the instructors during step 1 when they focused on the TE goals.

However, the instructors' scaffolding also depends on the focus task. For right turns, the two instructors supported the step 3 driving activity for about $50 \%$ of the tasks completed relating to TE goals and RU goals whereas they did not assist in completing the SI goal. For left turns, there is a high rate of instructor intervention for all three types of goal in step 2 . This rate clearly decreased in step 3 , but it remained around 0.4 even for IS goals. As with right turns, the rate of instructor intervention continued to decrease until the last lesson for left turns.

In contrast to turning tasks, the rate of instructor intervention was highest for RU goals throughout the training for overtaking (until the last lesson).

With regard to the conditional sub-goals, it may be underlined that the instructors continued to support students until step 3, whereas instructors delegated these tasks from the first lesson of training (cf. Fig. 3) and they are supposed to have been acquired at the end of step 1 . 


\begin{tabular}{|c|c|c|c|}
\hline & \multicolumn{3}{|c|}{ Tasks } \\
\hline & Turn-right & Turn-left & Overtaking \\
\hline \multirow{2}{*}{$\begin{array}{l}\text { Identification } \\
\text { of situation }\end{array}$} & \multicolumn{2}{|c|}{ Detect the intersection } & Detect the obstacle \\
\hline & \multicolumn{2}{|c|}{ Understand the intesection rules } & Understand the driving rules \\
\hline \multirow{2}{*}{$\begin{array}{l}\text { Other road } \\
\text { users oriented }\end{array}$} & \multicolumn{3}{|c|}{ Use turn indicator to inform } \\
\hline & \multicolumn{3}{|c|}{ Watch other road users } \\
\hline \multirow{5}{*}{ Technical } & $\begin{array}{c}\text { Drive on the right- } \\
\text { hand lane }\end{array}$ & $\begin{array}{c}\text { Drive on the left- } \\
\text { hand lane }\end{array}$ & Shift lane \\
\hline & Turning right & Turning left & \\
\hline & \multicolumn{2}{|c|}{ Set the vehicle right after the rotation } & \\
\hline & \multicolumn{2}{|c|}{ Cross-flow } & \\
\hline & \multicolumn{2}{|c|}{ Cross a pedestrian crossing } & \\
\hline $\begin{array}{l}\text { Conditional } \\
\text { Technical } \\
\text { sub-goals }\end{array}$ & \multicolumn{3}{|c|}{ Stop / (Re)-start / Shift gears } \\
\hline
\end{tabular}

Fig. 2. Categories of (sub-) goals for the focus tasks.

\subsection{Effect of instructors' activity on student performance}

We estimated the student performance on the focus from the percentage of tasks completed without instructor intervention (Fig. 5). The students increasingly completed the three types of driving task without instructor intervention as the training progressed (Fig. 5). By the end of the training, the students autonomously completed about $80 \%$ of all occurrences of the focus tasks. These results indirectly attested to the development of the students' driving skills, given that the instructors increased the

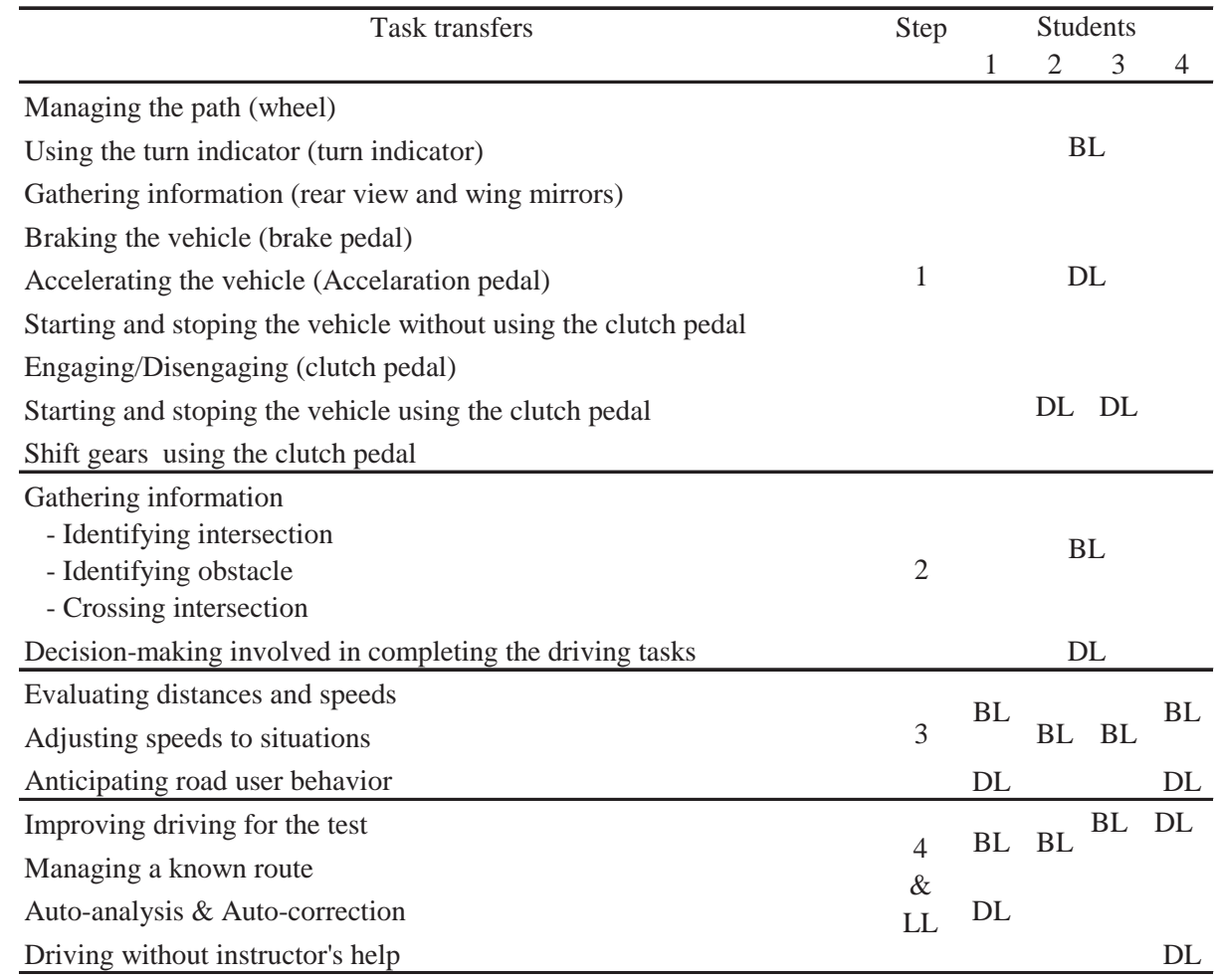

Fig. 3. Moment of driving task transfer from instructors to students per step. Note: $\mathrm{BL}=$ beginning of the lesson, $\mathrm{DL}=\mathrm{during}$ the lesson. 


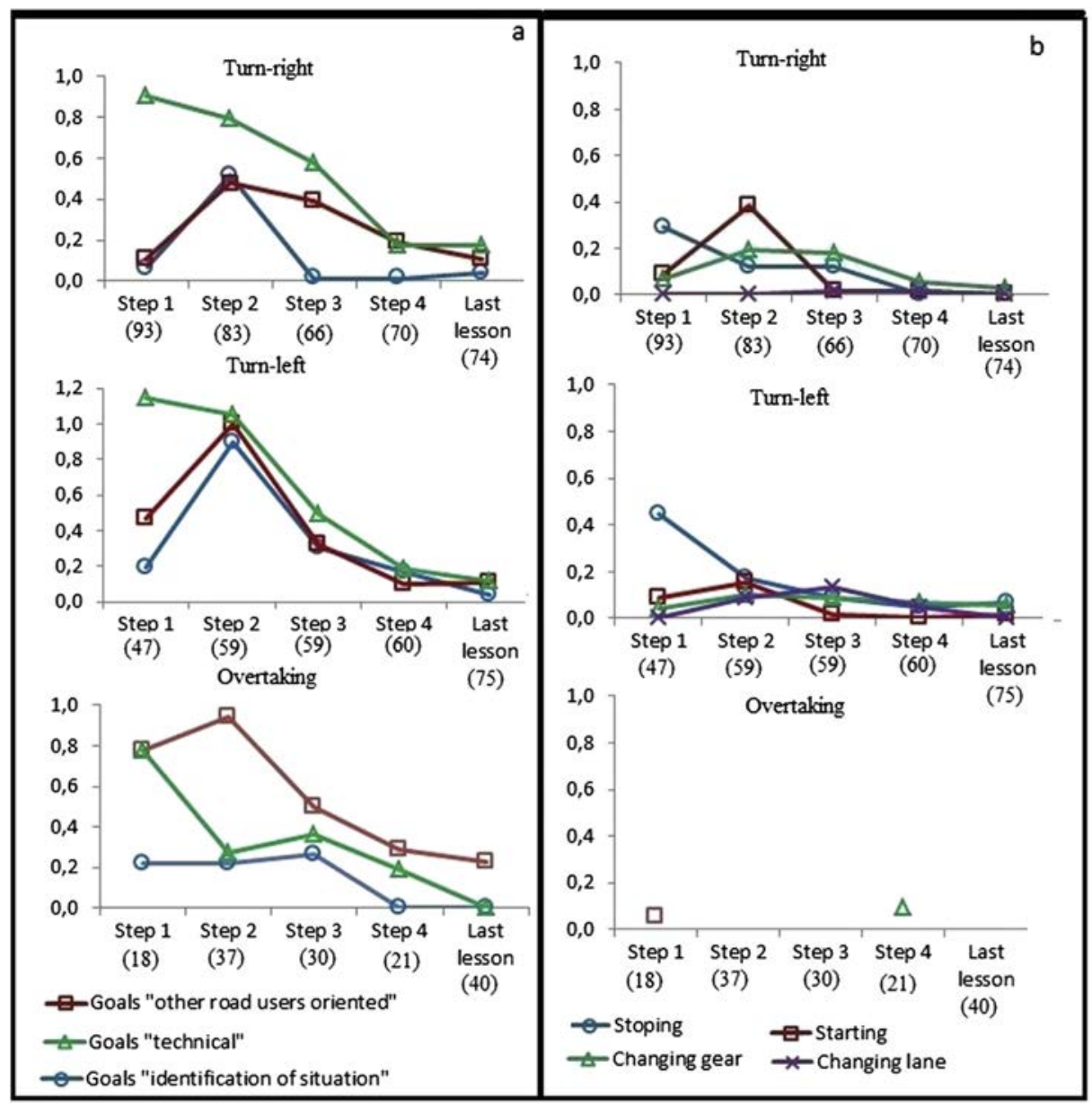

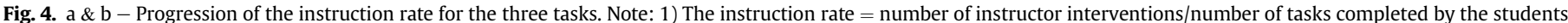

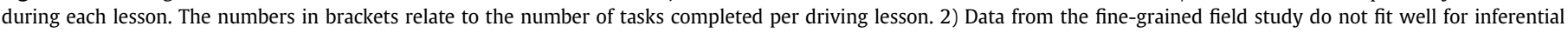

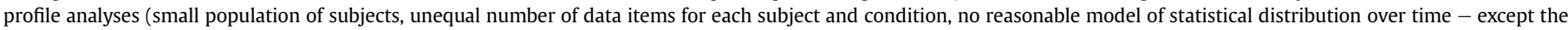

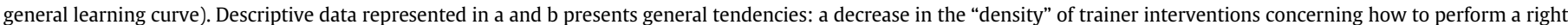

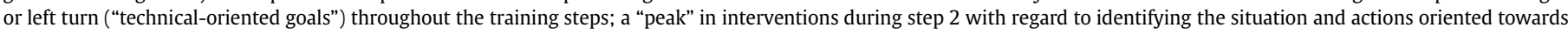

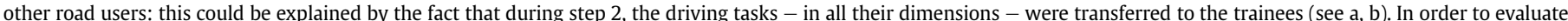

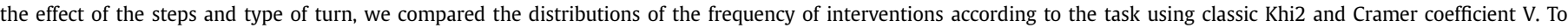

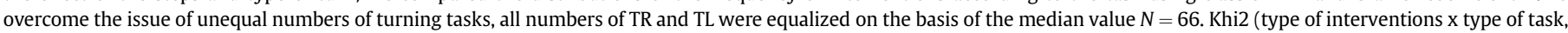

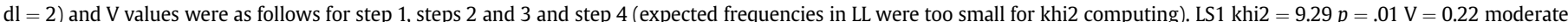
effect LS2 khi2 $=3.04 p=.10 \mathrm{~ns} \mathrm{~V}=0.09$ weak effect LS3 khi2 $=17.16 p=.001 \mathrm{~V}=0.35$ moderate to strong effect LS4 khi2 $=10.97 p=.001 \mathrm{~V}=0.43$ strong effect.

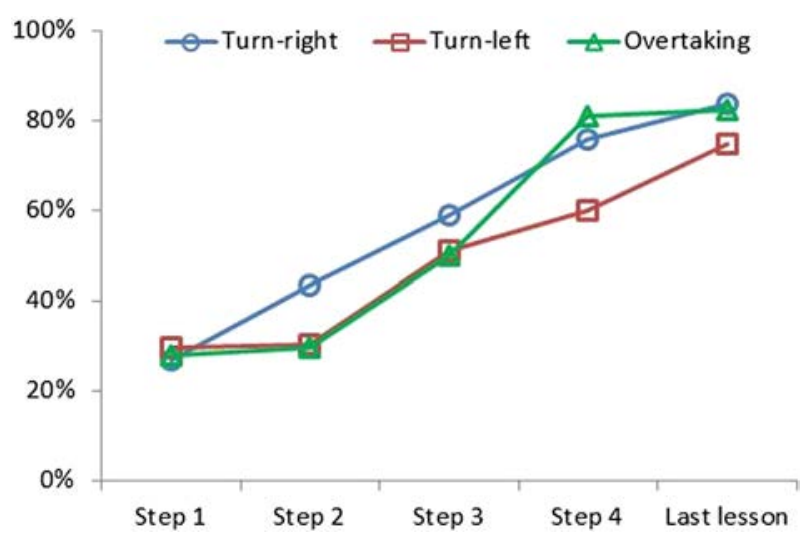

Fig. 5. Percentage of tasks achieved by the students without instructor intervention throughout training. complexity of the driving tasks throughout the training. It should be noted that the development of students' driving skills was similar for the three focus tasks in the context of complex urban traffic.

\section{Discussion and conclusion}

The aim of the present study was to offer a better understanding of the scaffolding activity of instructors during driving lessons, according to the concept of zone of proximal development (Vygotski, 1962/1986). Our analysis concerned three focus tasks which are performed frequently in urban areas in France during driver training (Boccara, 2011) and are risky for novice drivers and during lay instruction (Twisk et al., 2006; Twisk, 1994 1995; Gregersen et al., 2003): turning right, turning left and overtaking. 
As previous research has shown (Groeger and Cleg, 2000, 2007), the number of instructors' interventions decreased during training. Our method enabled us to draw more precise conclusions: the decrease in specific instructor interventions offered indications of the timeline of scaffolding fade-out. First, decoupling driving tasks constitutes a main element of this trainer scaffolding activity. It is complemented by their interventions (both verbal and physical) and by their choice of didactic driving situation (the progression of task transfer from trainer to trainee and the evolution of their interventions also indicate trainers' choices). Second, the two trainers organized the progression in a similar way: at the beginning of training, learning focused on the technical goals of turning right or left (drive on the right/left, turn, cross flow, etc.). Instructors progressively transferred the vehicle controls to the students, thereby increasing the complexity of the driving task while offering considerable support with regard to two other goals (identification of situations and road useroriented controls). From the middle of the training, the three categories of goals were transferred to the students, although instructors continued to provide students with a certain level of support.

The analysis conducted on the three focus tasks also showed that the learning process was supported by instructors in an integrative way, as stressed in previous research (Vidal-Gomel and Rogalski, 2007; Weill-Fassina, 2005). For instance, TE goals were an object of support throughout training and not only during the first step as recommended in the French training curriculum. These goals were supported by a combination of operations involved in using the vehicle controls, achieving conditional tasks [conditional sub-goals such as stop, (re)start, etc.] and performing the focus tasks. Three dimensions of Lefebvre's driving model (2001) were combined in the student process: "instrumental control of the vehicle", "adaptation to environment and traffic" and "planning course organization". Students learned to manage driving goals and conditional subgoals simultaneously rather than successively. Finally, the training curriculum, which constitutes the trainers' prescribed tasks, seems to be not an effective resource in the definition and organization of the training progression. Further researches could explore deeper this topic.

As the training analyzed took place in an urban area, questions arose concerning the generalization of the results. On country roads, pedestrians are less in evidence within the driving environment and the driver only has to manage two dynamics (Lefebvre, 2001): the inertia of his own vehicle and the speed of (any) vehicles travelling in the opposite direction. However, both dynamics are "stronger" than those in an urban area. Left-turn tasks imply more precise "time-window" evaluation and technical skills which must be adapted to higher speeds. The issue is unresolved with regard to how the instructors' activity is modified by such changes in environmental constraints. This requires further study comparing instructors' scaffolding activity in country and urban areas and their effects on the student learning process.

Returning to the method, we should emphasize that it is very costly in time and human resources, therefore limiting the number of dyads in the study. One way to improve it could be to use another level of coding and a transversal method with a wider sample of dyads. However, the results of the present study would seem to provide information on the prospects for improving student learning that also involves improving the training of instructors, as suggested by several European projects (MERIT, 2005; TRAINER, 2002). Instructors' scaffolding activity is organized along three lines: 1) the "decoupling" of the driving task and the gradual transfer of the driving task to the students, 2) the adaptation of content and rate of didactical intervention, and 3) the complexity of driving situations. Currently, these didactic dimensions are absent from the training programs which are nevertheless reference tools in the French context as well as in the proposed improvements in European projects (MERIT, 2005; TRAINER, 2002). Trainers themselves must therefore determine their own means of acting on student progress. It would therefore be desirable for these didactic dimensions to become an explicit objective of instructor training. For example, this could be implemented using scenarios featuring students at different levels of progress in achieving driving tasks such as turning left or right in order to encourage future instructors to reflect and act on their scaffolding activity with these students as well as their choice of the geographical driving zone for the lessons according to the different driving contexts available (traffic, infrastructure, speed limits, other road users). Similarly, this could also be one goal of training sessions supervised by an instructor trainer. In these situations, the future trainer would conduct a driving lesson with a student under the guidance of an instructor trainer in real traffic conditions. This type of instructor training session already exists in France, but without taking this type of didactic goal into account. In both cases, a debriefing session focusing on decoupling and transfer could be envisaged to support and improve the development of trainers' skills through reflexive activity.

Furthermore, such a perspective also needs to consider the difficulties encountered by novice instructors in diagnosing the level of students' skills development and their potential progress in order to make appropriate teaching choices (Vidal-Gomel et al., 2012) and identify geographical zones offering the characteristics of driving situations necessary to the student learning process (Weill-Fassina, 2005).

Furthermore, the analysis shows that students did not autonomously manage the navigation task at the end of training, but that instructor interventions concerning navigation evolved as training progressed. At the beginning, instructors provided total support for navigation by informing the student of each direction to take: "we will try to take the next right" (Appendix A, line 1). They gradually transferred navigation in part to the student by only announcing the direction with the city's name or the place to be reached. Students then had to identify the situation and make decisions in relation to the required navigation: turn left, turn right or go straight on, thereby combining levels 2 and 3 of Lefebvre's driving model (2001). The results therefore suggest that instructors did not completely uncouple the decision-making dimension as was related in previous research (MERIT, 2005), instead being subject to the situational constraints of training students in heavily built-up urban areas. However, this could impact a novice driver's safety after passing the driving test as navigation means managing a dual task - driving and navigating, specifically in unknown traffic areas with or without the use of GPS. This point should be examined in-depth in future analyses.

\section{Acknowledgment}

We thank the students, instructors and driving schools for having participated in this study. We would also like to extend our thanks to the reviewers for their critical work which helped us not only for the present paper but also for future analyses of the data we collected on driving students' skills development and instructors' teaching activities. 
Appendix A. Example of the coding scheme for comments and actions during a right-turn task during step 2.

\begin{tabular}{|c|c|c|c|c|c|c|c|c|c|}
\hline Line & Time & Actor & Verbatim & Predicate & Argument 1 & Argument 2 & Goals & Actor & Action \\
\hline 1 & $53: 26$ & Inst_1 & we will try to take the next right ... & Request & Goal & Navigation & Nav & Stud_1 & Drive straight \\
\hline 2 & $53: 29$ & Inst_1 & Finally, as soon as possible ... & Enunciate & Rule & Turn-right & $\mathrm{TE}$ & Stud_1 & Drive straight \\
\hline 3 & $53: 31$ & Inst_1 & I don't know why this is, but ... & Delegate & Identification & Turn-right & IS & Stud_1 & Drive straight \\
\hline 4 & $53: 33$ & Inst_- 1 & then, you see things? & Request & Identification & Signalisation & IS & Stud_1 & Drive straight \\
\hline 5 & $53: 36$ & Stud__1 & there, I see a red light. & Enunciate & Identification & Signalisation & IS & Stud_1 & Drive straight \\
\hline 6 & $53: 43$ & Inst_1 & you see a street? & Question & Identification & Intersection & IS & Stud_1 & Drive straight \\
\hline 7 & $53: 44$ & & & & & & & Stud_1 & Stop \\
\hline 8 & $53: 46$ & Stud_1 & I see a small street on the right. & Enunciate & Identification & Intersection & IS & Stud_1 & Wait \\
\hline 9 & $53: 47$ & Inst_1 & $\mathrm{hmm} \ldots$ & Approve & & & & Stud_1 & Wait \\
\hline 10 & $53: 51$ & Stud__l 1 & which is not prohibited. & Enunciate & Identification & Signalisation & IS & Stud_1 & Wait \\
\hline 11 & $53: 54$ & & & & & & & Stud_1 & Wait \\
\hline 12 & $53: 58$ & Stud_1 & and no, then I can't see anything ... & Enunciate & Identification & & IS & Stud_1 & Wait \\
\hline 13 & $54: 00$ & Inst_1 & if it is not prohibited, we will try to take it. & Request & Goal & Navigation & $\mathrm{Nav}$ & Stud_1 & Wait \\
\hline 14 & $54: 03$ & Stud_ 1 & I think it is not prohibited. & Enunciate & Identification & Signalisation & IS & Stud_1 & Wait \\
\hline 15 & 54:06 & Inst_1 & we will see in approaching ... & Enunciate & Procedure & Signalisation & IS & Stud_1 & Wait \\
\hline 16 & $54: 08$ & Inst_1 & how to know if it is prohibited or not? & Question & Knowledge & Signalisation & IS & Stud_1 & Wait \\
\hline 17 & $54: 09$ & & & & & & & Stud_1 & Re-Start \\
\hline 18 & $54: 11$ & Inst_1 & either with a one-way signs... & Enunciate & Indicator & Signalisation & IS & Stud_1 & Drive straight \\
\hline 19 & $54: 13$ & Inst_1 & or? & Question & Indicator & Signalisation & IS & Stud_1 & Drive straight \\
\hline 20 & $54: 13$ & Stud__1 & with the markings on the ground... & Enunciate & Indicator & Signalisation & IS & Stud_1 & Stop \\
\hline 21 & $54: 15$ & Inst_1 & or with the parking signs. & Correct & Indicator & Signalisation & IS & Stud_1 & Wait \\
\hline 22 & $54: 17$ & Stud_-1 & euh, really? & Realize & Indicator & Signalisation & IS & Stud_1 & Re-Start \\
\hline 23 & $54: 20$ & Inst_1 & bah yes, if the parking signs are to us ... & Explain & Indicator & Signalisation & IS & Stud_1 & Drive straight \\
\hline 24 & $54: 22$ & Inst_1 & it means we can get into it, necessarily. & Explain & Indicator & Signalisation & IS & Stud_1 & Drive straight \\
\hline 25 & $54: 23$ & Stud̄_1 & yeah, yeah, yeah. & Approuve & & & IS & Stud_1 & Drive straight \\
\hline 26 & $54: 23$ & Inst_1 & turn-light. & Guide & Procedure & Turn-right & RU & Stud_1 & Drive straight \\
\hline 27 & $54: 24$ & & & & & & & Stud_1 & Use turn-light \\
\hline 28 & $54: 26$ & & & & & & & Stud_1 & Turn-right \\
\hline 29 & $54: 31$ & Inst 1 & in addition, there is even one on the left side. & Enunciate & Indicator & Signalisation & IS & Stud_1 & Turn-right \\
\hline 30 & $54: 33$ & Inst_ 1 & parking sign. & Enunciate & Indicator & Signalisation & IS & Stud_1 & Turn-right \\
\hline 31 & $54: 37$ & & & & & & & Stud_1 & Shift second gear \\
\hline 32 & $54: 38$ & Inst_1 & no? & Question & Identification & Signalisation & IS & Stud_1 & Drive straight \\
\hline 33 & $54: 38$ & Stud__1 & yes, yes, yes. & Approuve & Identification & Signalisation & IS & Stud_1 & Drive straight \\
\hline 34 & $54: 39$ & Inst_1 & if it is directed towards us, does that mean? & Question & Indicator & Signalisation & IS & Stud_1 & Drive straight \\
\hline 35 & $54: 41$ & Stud̄_1 & bah, you can park on the left. & Enunciate & Rule & Signalisation & IS & Stud_1 & Drive straight \\
\hline 36 & $54: 43$ & Inst_1 & and? & Question & Indicator & Signalisation & IS & Stud_1 & Drive straight \\
\hline 37 & $54: 45$ & & & & & & & Stud_1 & Watch to the right \\
\hline 38 & $54: 46$ & Stud_1 & and right, right? & Enunciate & Rule & Turn-right & $\mathrm{TE}$ & Stud_1 & Drive straight \\
\hline 39 & $54: 47$ & Inst_1 & and right. & Confirme & Rule & Turn-right & $\mathrm{TE}$ & Stud_1 & Drive straight \\
\hline 40 & $54: 47$ & Inst_1 & and therefore, theoretically it's called? & Question & Knowledge & Signalisation & IS & Stud_1 & Drive straight \\
\hline 41 & $54: 49$ & Stud_1 & one-way streets? & Enunciate & Knowledge & Signalisation & IS & Stud_1 & Turn-right \\
\hline 42 & $54: 51$ & Inst_1 & and yeah. & Confirme & Knowledge & Signalisation & IS & Stud_1 & Turn-right \\
\hline 43 & $54: 54$ & & & & & & & Stud_1 & Drive straight \\
\hline
\end{tabular}

The gray shade is to facilitate the reading and the identification of who is the actor speaking. In gray, it is the student and in black it is the instructor.

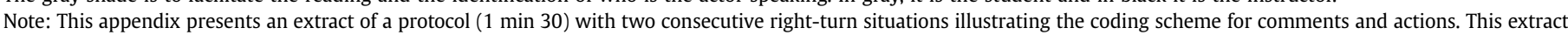

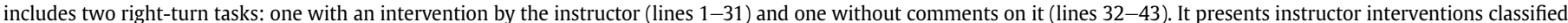

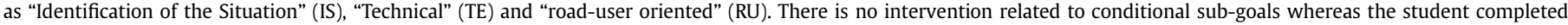
several of them, without instructor intervention (e.g. lines 7, 17, 20, 22 and 31).

\section{References}

ADVANCED, 2002. The EU Advanced Project: Description and Analysis of Postlicence Driver and Rider Training. Final report. CIECA, The Hague, Netherlands. Amalberti, R., Hoc, J.-M., 1998. Analyses des activités cognitives en situation dynamique: pour quels buts ? Comment ? Le. Trav. Hum. 61 (2), 207-234.

Beanland, V., Goode, N., Salmon, P.M., Lenné, M.G., 2013. Is there a case for driver training? A review of the efficacy of pre- and post-licence driver training. Saf. Sci. 51 (1), 127-137. http://dx.doi.org/10.1016/j.ssci.2012.06.021.

Boccara, V., 2011. Développement des compétences en situation de tutelle au cours de la formation à la conduite automobile. Apports croisés de la psychologie ergonomique et de la psychologie sociale. Doctorat de psychologie ergonomique. Université Paris 8 - Vincenens - Saint-Denis, Saint-Denis (France).

Boccara, V., Delhomme, P., Vidal-Gomel, C., Rogalski, J., 2011a. Development of student drivers' self-assessment accuracy during French driver training: selfassessments compared to instructors' assessments in three risky driving situations. Accid. anal. Prev. 43 (4), 1488-1496.

Boccara, V., Delhomme, P., Vidal-Gomel, C., Rogalski, J., 2011b. Time course of driving-skill self-assessments during French driver training. Accid. Anal. Prev. 43 (1), 241-246.

Brown, K.W., Cozby, P.C., Kee, D.W., Worden, P.E., 1999. Research Methods in Human Development. Mayfield Publishing Company, Mountain View, California.
Daniellou, F., 2005. The French-speaking ergonomists' approach to work activity: cross-influences of field intervention and conceptual models. Theor. Issues Ergon. Sci. 6 (5), 409-427.

Daniellou, F., Rabardel, P., 2005. Activity-oriented approaches to ergonomics: some traditions and communities. Theor. Issues Ergon. Sci. 6 (5), 353-357.

DSCR, 2005. Le livret d'apprentissage. Véhicules légers. Guide technique de sécurité routière. La documentation française, Paris.

Gasson, S., 2004. Rigor in grounded theory research: an interpretive perspective on generating theory from qualitative field studies. In: Whitman, M.E. Woszczynski, A.B. (Eds.), The Handbook of Information Systems Research. Idea Group, Hershey, PA, pp. 79-102.

Gregersen, N.P., Nyberg, A., Berg, H.-Y., 2003. Accident involvement among learner drivers - an analysis of the consequences of supervised practice. Accid. Anal. Prev. 35 (5), 725-730.

Groeger, J.A., 2000. Understanding Driving: Applying Cognitive Psychology to a Complex Everyday Task. Psychology Press, Hove (UK).

Groeger, J.A., Clegg, B.A., 2000. Practice and Instruction When Learning to Drive. Road Research Report No. 14. HMSO, London.

Groeger, J.A., Clegg, B.A., 2007. Systematic changes in the rate of instruction during driver training. Appl. Cogn. Psychol. 21 (9), 1222-1244. 
Hacker, W., 1985. On some fundamentals of action regulation. In: Ginsburg, G.P., Brenner, M., von Cranach, M. (Eds.), Discovery Strategies in the Psychology of Action. Academics Press, London (UK), pp. 63-84.

Hatakka, M., Keskinen, E., Gregersen, N.P., Glad, A., Hernetkoski, K., 2002. From control of the vehicle to personal self-control broadening the perspectives to driver education. Transp. Res. Part 5, 201-215.

INSERR, 2008. Recherches et pratiques éducatives innovantes pour l'accès au permis de conduire en Europe. In: Actes du séminaire du 28 mars 2008. Paris, La défence (France).

Lefebvre, C., 2001. Vers une formation à la conduite automobile intégrant des connaissances conceptuelles et métaconnaissances. Rech. Transp. Sécurité 70,16-40.

Leplat, J., 1990. Relations between task and activity: elements for elaborating a framework for error analysis. Ergonomics 33 (10/11), 1389-1402.

Leplat, J., 1997. Regards sur l'activité en situation de travail. Contribution à la psychologie ergonomique, PUF, Paris.

MERIT, 2005. Minimum Requirement for Driving Instructor Training. European Project. Contrat (DG TREN) SER-b27020b-e3 Driving Instructors S07.28913. Institute Gute Fahrt, Vienna (Austria).

NOVEV, 2004. Evaluation of Novice Driver Training Schemes in 6 EU-member States. CIECA, Bruxelles (Belgium).

Rismark, M., Solvberg, A.M., 2007. Effective dialogues in driver education. Accid. Anal. Prev. 39 (3), 600-605.

Rogalski, J. 2003. Y a-t-il un pilote dans la classe ?: une analyse de l'activite l'enseignant comme gestion d'un environnement dynamique ouvert. Rech. didact. mathématiques 23, 343-388.

Rogalski, J., 2005. Cognitive ergonomics, discourse analysis and didactics for the analysis of teachers' and trainers' activity. In: Marmaras, N., Kontogiannis, K. Nathanael, D. (Eds.), Proceedings of EACE'05, ISBN 960-254 656-5, pp. 123-130. Chania, Grèce.
Samurçay, R., Rogalski, J., 1998. Exploitation didactique des situations de simulation. Le. Trav. Hum. 61 (4), 333-359.

Siegrist, S., 1999. Driver Training, Testing and Licensing - Towards Theory-based Management of Young Driver'injuries Risk in Road Trafic. Results EU-project GADGET. BFU, Berne (Switzerland).

TRAINER, 2002. System for Driver Training and Assessment Using Interactive Evaluation Tools and Reliable Methodologies. CIECA, Bruxelles (Belgium).

Twisk, D.A.M., 1994. Young Driver Accidents in Europe. SWOV, Leidschendam.

Twisk, D.A.M., 1995. The Accident Liability of Young/novice Drivers and the Effectiveness of Driver Licensing Systems. SWOW, Leidschendam (Sweden).

Twisk, D.A.M., Gregersen, N.P., Assailly, J.P., 2006. Young Drivers: the Road to Safety. OCDE/CEMT, Paris (France).

Valot, C., Amalberti, R., 1992. Metaknowledge for time and reliability. Reliab. Eng. Syst. Saf. 36 (3), 199-206.

Vidal-Gomel, C., Rogalski, J., 2007. Driver training: the collective dimension in trainers' activity. In: Brinkman, W.-P., Ham, D.-H., Wong, W. (Eds.), ECCE 2007Invent! Explore!, ISBN 978-1-84799-849-1, pp. 111-118. London, UK.

Vidal-Gomel, C., Boccara, V., Rogalski, J., Delhomme, P., 2012. Sharing the drivingcourse of a same trainee between different trainers, what are the consequences? Work: J. Prev. Assess. Rehabil. 41, 205-215.

Vygotsky, L.S., 1962/1986. Thought and Language. MIT Press, Cambridge (MA).

Weill-Fassina, A., 2005. Modalités de transmission par des moniteurs d'auto-école en fonction de leur ancienneté dans le métier. In: Actes du séminaire Vieillissement et travail: "Transmission des savoirs professionnels en entreprise ", $n^{\circ}$ 35. CREAPT-CEE, Noisy-le-Grand, pp. 95-110 décembre 2006. http://www. cee-recherche.fr/fr/rapports/actes_vieillissement_travail_2005_35.pdf.

Wood, D., Bruner, J., Ross, G., 1976. The role of tutoring in problem solving. J. Child. Psychol. Psychiatry 17, 89-100. 